\title{
Technology And Online Education: Models For Change
}

Catherine W. Cook, Florida Institute of Technology, USA

Christian Sonnenberg, Florida Institute of Technology, USA

\begin{abstract}
This paper contends that technology changes advance online education. A number of mobile computing and transformative technologies will be examined and incorporated into a descriptive study. The object of the study will be to design innovative mobile awareness models seeking to understand technology changes for mobile devices and how they can be used for online learning. These models will take information from technology vicissitudes, online education systems, along with mobile device literature, and build a picture of past, current, and future trends for online learning. The application of such an approach should lead to a better definition of mobile awareness requirements and greater online visibility relative to selection of the appropriate model criteria and requirements. The models will identify online problem definitions, hardware and software advancements, analysis mobile objectives, and the selection of evaluation criteria and requirements to design online mobile awareness. By using technology vicissitudes, online education systems, and mobile device variables that are found in the literature, models can be designed to achieve awareness for online learning and changing technologies. These futuristic models can help to identify the appropriate techniques and methods to be used in facilitating the overall effort in future mobile devices for online learning. Hopefully, seamless technology integration and borderless networks for mobile awareness will motivate and benefit all future online teaching and learning groups.
\end{abstract}

Keywords: Technology; Online Education; Mobile Devices; Hardware Advances; Software Advances; Models

\section{INTRODUCTION}

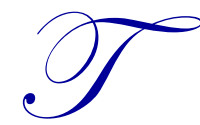

echnology, online education, and students continue to change. As technological innovation occurs involving the Internet and computer software, we need to think of new progressions for online education. With this awareness, educators need to deliver a positive and innovative experience for every online student. Educators must consider different approaches to online design and development that considers mobile responsive. The goal is to create mobile friendly visual framework that allows for comprehensive viewing in all online environments. Keeping in mind that online learning can take place anywhere, anytime - the increase of mobile devices can create new online educational direction. This direction, using collaboration tools, can allow professors, students, and remote experts to visually connect with each other. Collaborate tools can allow for information being more accessible and that can result in new models of online learning. Collaborate tools and their applications can create models of borderless online networks. Thus, the approach of borderless networks can create dynamic online learning opportunities.

Before reconnoitering online education, one has to define technology that allowed the online landscape to be created. According to Shane (2009), technology was the application of materials, processes, techniques, and tools for human activity. Next, we must define both invention and innovation in relation to technology. Shane (2009) defined invention as the discovery of a new idea that creates knowledge to solve a problem and innovation as the process of using knowledge to solve a problem. Given these definitions, we perceived that technological innovation was the use of knowledge to apply materials, processes, techniques, and tools for human activity (Shane, 2009). 
Today, the World Wide Web (Web) is thriving within corporate workplaces and higher education campuses. The presence of the Web and online environment has changed the relationship between those who are entrusted to train and teacher - and those learners who will benefit from new online experiences. With this change, trainers, teachers, and learners can move towards a more active and collaborative learning experience. First, we must establish the current technologies driving our online landscape. Second, one has to consider the vested partners in that online landscape. Vested partners include business, government, and higher education. All will have consigned interest in designing, modeling, and developing new training, teaching, and learning paradigms (Berners-Lee, 1992; Berners-Lee \& Fischetti, 1999; Bates, 2012).

\section{TECHNOLOGY AND MOORE'S LAW}

In discussing technological advancements, a brief review of the literature is appropriate to gain an understanding of technology changes over the past several decades. Presently, we are undergoing a fast pace of technological advancement. This pace suggests that our current technologies are certainly powerful - but, may be only temporary. Moore's Law (1965) was related to computing hardware and posited that the number of transistors on integrated circuits would double approximately every two years. The law has been a guiding principle of progress in electronics and computing since Moore first formulated his predication in 1965. In the late 1950's, chips had 200 transistors. By 2005, chips with 1 billion transistors were produced by Intel (Moore, 1965; Kanellos, 2003). Moore (1965) foresaw the future of integrated electronics that would bring about a proliferation of electronics, pushing science into new areas. New areas would include sensations for home computers, automatic controls for automobiles, and personal portable communications equipment. Lastly, the new science would see the most potential in the production of large systems, such as telephone communications that would switch telephone circuits and perform data process, establishing powerful computers organized in completely different ways (Moore, 1965).

According to Kurzweil (1999), communications and internet technologies were projected to continue to evolve at the pace of Moore's Law for a minimum of another 20 years, and the Law of Accelerating Returns, meaning that the pace of advancement would continue to increase. Kurzweil (1999) proposed "The Law of Accelerating Returns," according to which the rate of change in a wide variety of evolutionary systems (including the growth of technologies) tended to increase exponentially. Simply put, accelerating change could be viewed as an increase in the rate of technological progress throughout history, which suggested faster and more profound changes in the future. Kurzweil (2001) argued for extending Moore's Law to describe exponential growth of diverse forms of technological progress, suggesting new technology will be invented to allow us to cross barriers, such as disruptive technologies. Overcoming disruptive technologies leads to invention and innovation - in turn accelerates technology adoption. Thus, identifying and understanding the barriers will lead to seamless technology integration and borderless networks that will motivate and benefit future training, teaching, and learning groups.

Keeping Moore's Law in mind, we need to investigate the technologies supporting the paradigm of online learning that is with us now. Have we seen, since the early 1950's, communications and Internet technologies evolved at the pace of Moore's Law for a minimum of 20 years and the Law of Accelerating Returns? Put simply, are technology changes continuing to increase as Moore's Law would suggest? We can answer that question by looking at the technologies that are presently serving our training, teaching, and learning groups. The global world has been with us for over 35 years. Technological developments, such as the Internet, the Web, mobile and wireless computing, and their related applications, allowed for the creation and expansion of a global world (Boettcher \& Conrad, 2004). During those 35 years, and certainly within the last 10 years, our technologies have transformed how people interact and collaborate with each other. Our technologies have transformed how we use our resources and services. Finally, our technologies have transformed how organizations, such as business, government, and education, function in a global world (Boettcher \& Conrad, 2004).

\section{TECHNOLOGY INNOVATIONS 1950-2010}

We can trace the development of electronic computers to the late 1950's. Early networking formulated in the Cold War think tanks and was realized in the Defense Department with its creation of the Advanced Research Projects Agency Network (ARPANET). In 1966, associates at MIT proposed a plan for the first long-distance computer network. In 1967, Lawrence Roberts carried out research into computer networks and is credited with the 
system design for the wide area digital communications network that would come to be called ARPANET (Roberts, 1967; Abbate, 1999). Roberts (1967) listed five reasons for establishing a network which would allow many computers to communicate with each other to interchange and execute programs or data: load sharing; message service; data sharing; program sharing; and, remote service. The concept of the Internet developed in the late 1960's and early 1980's with a variety of protocols. In particular, the ARPANET, led to the development of federal wide area network protocols for internetworking, which were multiple separate networks, joined together into a network of networks (Roberts, 1967; Abbate, 1999). In 1974, Transfer Control Protocol/Internet Protocol (TCP/IP) allowed computers and networks of different varieties to connect to each other for the first time. In 1982, Internet protocol suite was standardized, leading to the concept of world-wide network of interconnected networks, called the Internet. Access to the ARPANET was expanded in the 1981 and later in 1986, leading to supercomputer sites in the United States for research and education organizations (Roberts, 1967; Abbate, 1999; Barras, 2007). Eventually, there were collaborations between business, government, and universities, which led to rapid progress in the development of the Internet.

It was advocated by Bower and Christensen (1995) along with Rosenbloom and Spencer (1996) that our technologies have innovated faster than society's needs evolved. Technologies produce services that are at the beginning sophisticated, expensive, and complicated for the marketplace. These are sustaining technology innovations for the higher tiers of their markets, going to the most demanding and sophisticated customers at the top of the market. However, by doing so, these technology innovations open the door to "disruptive innovations" at the bottom of the market (see Table 1).

Table 1: Phases of Technology Innovations

\begin{tabular}{|l|l|}
\hline $1960-1980$ & $\begin{array}{l}\text { Internet introduced and development of supercomputer sites in the United States for research and } \\
\text { Incremental Phase }\end{array}$ \\
\hline $\begin{array}{l}1990-2010 \\
\text { Semi-Radical Phase }\end{array}$ & $\begin{array}{l}\text { advancement in technological capacity to store, communicate, compute information, tracking, and } \\
\text { digital technologies }\end{array}$ \\
\hline $\begin{array}{l}2010 \text { - present } \\
\text { Disruptive Phase }\end{array}$ & digital format in telecommunication and technological memory \\
\hline
\end{tabular}

Source: Bower and Christensen (1995); Rosenbloom \& Spencer (1996)

Simply put, a disruptive innovation is an innovation that helps create a new market and eventually goes on to disrupt an existing market, displacing an earlier technology (Bower \& Christensen, 1995; Rosenbloom, 1999). An example of disruptive innovation can be illustrated with the online environment comparison to the traditional onground higher education. There are several disruptive innovations that are now providing students with alternatives to the on-ground traditional higher education. Students may elect to take online courses, blended learning, and structured career-focused learning. By selecting these online choices, students are disrupting on-ground traditional higher education. Technology innovation is important; it is a source of value creation. Specifically, value creation has application of knowledge to human activity, allowing for the more efficient production of existing products and services for online education (Shane, 2009).

\section{TECHNOLOGY CHANGES 2010-PRESENT}

Technology changes from 2010 to the present (see Table 2), uses products and methods created from past technological ideas and leading to disruptive technology in a three step process: incremental innovative technology, which is an improvement in a product or method (e.g., taking the latest version of a word processing program and creating new types of efficient tools for documentation); semi-radical, in which innovative technology relies on existing technological knowledge, but uses the knowledge in a different way (e.g., mobile phones that have become cell phones which are today personal communication networks); and innovative disruptive technological, which breaks from the past by pushing aside existing businesses and their supply chains (e.g., digital photography minimized traditional cameras and film) (Schatzberg, 2006).

Today, the use of mobile wireless technologies such as mobile phones, tablets, and laptops is in use for online education. The advantage for these devices is portability and speed. The question remains, what will tomorrow bring for the online environment? What must be recognized is that technology changes lead to a transition that continuously challenges online education. What must be advanced are educational technologies to 
support new directions for the new e-Learning environment. This new online landscape must align itself with both educators and student expectations and the technological drivers. The challenges in this evolving direction will test current online practices along with the vehicle with which to deliver the online learning experiences. Emerging technological developments such as mobile computing and synchronous lecture engagement activities must evolve to meet the future needs of expectations for all online users (Balakrishnan \& Lay, 2013; Yates, 2013).

Table 2: Technology Changes 2010 to Present

\begin{tabular}{|l|l|}
\hline Incremental Changes & $\begin{array}{l}\text { incremental innovative technology, which is an improvement in a product or method (e.g., taking the } \\
\text { latest version of a word processing program and creating new types of efficient tools for } \\
\text { documentation) }\end{array}$ \\
\hline $\begin{array}{l}\text { Semi-Radical } \\
\text { Changes }\end{array}$ & $\begin{array}{l}\text { semi-radical, which innovative technology relies on existing technological knowledge, but uses the } \\
\text { knowledge in a different way (e.g., mobile phones that have become cell phones which are today } \\
\text { personal communication networks) }\end{array}$ \\
\hline Disruptive Changes & $\begin{array}{l}\text { innovative disruptive technological, which breaks from the past by pushing aside existing businesses } \\
\text { and their supply chains (e.g., digital photography minimized traditional cameras and film; Internet } \\
\text { minimized the U. S. Postal service because of speed and convenience) }\end{array}$ \\
\hline
\end{tabular}

Source: Schatzberg (2006)

\section{INTERNET COMMUNICATION TOOLS 1990-2010}

Increasingly complex technologies have and will continue to revolutionize our way of communicating. From the invention of the movable type print by German Johannes Gutenberg in the $15^{\text {th }}$ century, to the advent of the Internet in the late 1980's, worldwide communications has continued to accelerate (Singer, Holmyard, \& Hall, 1958; Koscielniak, 2003). Communication has moved from printing, radio, telephone, cell phone to the Internet and digital technologies, videoconferencing, and Skype peer-to-peer Internet telephony protocols (Daft, \& Lengel, 1986; Baset \& Schulzrinne, 2004; Biondi \& Desclaux, 2006; Choudhry, 2013). This has allowed more people to gain access to broader areas of information. As a result, the Internet has become a major channel for communication around the world. The proliferation of technology changes in the late $20^{\text {th }}$ century and early $21^{\text {st }}$ century has made communication personal and powerful and has greatly impacted our culture and commerce (Maratos, 2012; Martell, 2013). The eight Internet communications tools from technological developments and prominently adapted for business, training, and online learning from 1990 to 2010 are shown in Table 3.

Table 3: Internet Communication Tools for Business, Training, and Online Education

\begin{tabular}{|l|l|}
\hline 1. World Wide Web & 5. Interactive video conferencing \\
\hline 2. Electronic Mail & 6. Skype \\
\hline 3. Instant Messaging (IM) & 7. Mobile/Smartphones \\
\hline 4. Voice over Internet Protocol (VoIP) & 8. Social Networks \\
\hline
\end{tabular}

Source: Fenell (2013)

We begin the review of the eight communication tools for this time period with the World Wide Web. Tim Berners-Lee was credited with the software program known as the World Wide Web (Web) in 1989. The popularity of the Web began to grow and eventually made an impact on business, government, communication, and education. The Web made it possible to retrieve and access documents on the Internet. Significantly, the Web made it possible for computer users around the world to connect to each other (Berners-Lee \& Fischetti, 1999; Fenell, 2013; The Conversation, 2013). The second communication tool for this time period was Email. Email was a function of the Internet and was virtually instant. Users could access it from numerous devices, such as cell phones, computers, and personal digital assistant (PDAs). The third communication tool was instant messaging. Instant messaging was done on keyboards over the Internet. However, instant messaging innovation may have reached its peak early in 2000 's, giving way to the more interactive social media platforms. The fourth communication tool was Voice over Internet Protocol (VoIP). VoIP was technology that bypassed the telephone network, allowing for voice calls using the Internet instead of a regular telephone line (Hsu, Lin, Sun, \& Chen, 2012; Fenell, 2013).

The fifth communication tool was Interactive video conferencing. Interactive video conferencing was a live video connection between people in separate locations for the purpose of commination or interaction, allowing people to communicate visually from anywhere in the world. With online video conferencing, any organization can 
communicate effectively with their key audience (Allison, 2013; Martell, 2013). Uses of video-conferencing has been a great benefit for distance learning, sharing lectures with students at other universities, giving and receiving lectures/presentations from remotely located sites around the world, and conducting meeting between research groups and academics based at different universities (Choudhry, 2013). The sixth communication tool was Skype. Skype was a peer-to-peer VoIP client developed by KaZaa in 2003 and it encrypts calls end-to-end while storing user information in a decentralized fashion (Baset \& Schulzrinne, 2004). Almost seamlessly, Skype allowed users to communicate with peers by voice using a microphone, video by using a webcam, and instant messaging over the internet (Biondi \& Desclaux, 2006; Fenell, 2013).

The seventh communication tool was the Mobile phone. Mobile phones were devices that could make and receive telephone calls over a radio link moving around a wide geographic area. Smartphones were mobile phones built on a mobile operating system. Mobile phones offered text messaging, Multimedia Messaging Service (MMS), email Internet access, short-range wireless communications, business applications, gaming, photography, and more general computing capabilities. We eventually see Smartphones with more advanced computing capability and connectivity than mobile phones. As a final point, Smartphones had the functionality of portable media players, compact digital cameras, pocket video cameras, Global Positioning System (GPS) navigation units for form one milt-use device with high-end resolution touchscreens and web browsers (Fenell, 2013). Lastly, the eighth communication tool was Social networks, such as Twitter and Facebook, which were forms of mass communication, where messages were spread to many recipients. Usage of social media sites has sparked and expanded communication within a community of friends and family. Social media technologies have facilitated social awareness that encouraged everyone to use social media and networking tools. The communities created by social media sites inspired more frequent collaboration and information between family and friends (Gruzd \& Staves, 2011).

Finally, from the literature review we can conclude the three Internet communication tools most favored by online educationalists; email, IM, and asynchronous discussions (text, Web based, messages sent via email). Email had the benefit of providing a written record of the online communication that transpired with speed and convenience. IM messaging was more instantaneous than email and users could include videos, images, files, links to websites, and sound. Of great value to online education are asynchronous discussions, which are an educational online tool by which professors and students could interact via discussions without the constraints of time and classroom. As a result, through the use of right Internet communication technologies, both educators and students developed new experiences in education (Borenstein, 1993; Tennenhouse, Garland, Kaashoek, \& Kaashoek, 1996; Chess, 1998).

\section{TECHNOLOGY AND ONLINE LEARNING}

Having reviewed the technology changes from the 1950's to the present, we can now focus on how these changes affected online learning during that time period. The early timeline of online education ranges from the 1950's to the 1980's. Recorded in 1959, Daniel Alper and Don Bitzer created PLATO, a home for the first internetbased community designed for learning purposes (Davis, 1980; Hobbes, 2011). The milestone event that recognized online education in the United States occurred at the University of Illinois during the 1960's, with a classroom system based in linked computer terminals. This was the first online learning experience, leading ultimately to education presented over the internet on a vast array if subjects. In 1968, the University of Alberta Department of Medicine began to offer rudimentary online courses. At the same time, the United Kingdom (UK) government created a wireless university. In 1969, the Open University was formed and distance teaching was introduced with online classes through the CICERO program (Hobbes, 2011; Maratos, 2012). Coastline Community College became the world's first fully remote community college in 1976. Lastly, the New Jersey Institute of Technology, through its computerized conferencing and communications center, began to study the outcomes of online and computerized learning environments and helped defined the electronic frontier (Hiltz, \& Turoff, 1993; Hobbes, 2011).

Before Web learning, training was available to organizations using mail and telegraph. As the computer industry started to expand in the 1980's, online training became a potential creation. The multimedia age was developing with the use of multimedia programs. Companies began online training for new employees and used 
multimedia programs to visually enhance presentations. As the 1990's ended, the millennium provided new technology for the computer industry. With computer industry expansion, e-training and multimedia was soon readily available for everyone. Corporate America started using PowerPoint to enhance company presentations. Without doubt, technology was moving forward with video games and other multimedia programs (Aranda, 2006). As these technological advances expanded, the first type of online education began in the mid-1990's. The millennium would mark a new period for technology with online education courses designed and developed for online learning. E-learning with online education courses became popular within both colleges and businesses. Rapidly, online education was aided with streaming media, online video access, and fast web site servers. This has led to online education and Internet training that provided people with a new incentive to learn (Aranda, 2006).

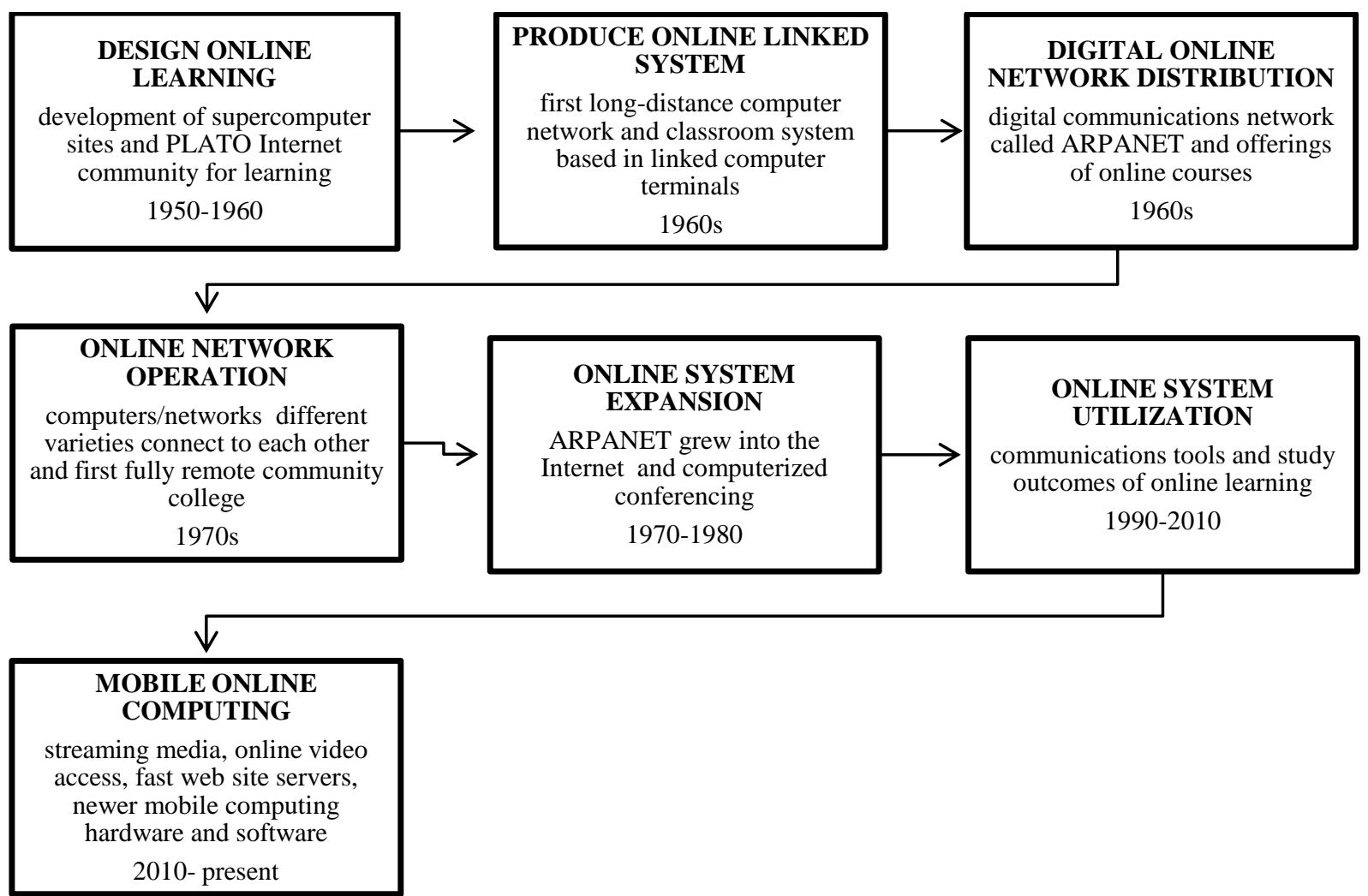

Model 1: Technology Change Model 1950 - 2010 (TCM)

Source: Aranda (2006); Cook \& Sonnenberg (2013)

From this literature review, a model of technological changes could be created for that time period (see Model 1). According to Al-Fedaghi (2009), information processing models have evolved since 1949 and methods have been proposed to extract requirements from policies and regulations using formal models. Modeling can be used as a tool for performance analysis and optimization strategies; modeling design can extend functionality in extracting valuable information and knowledge from model parameter settings. Modeling can explain the technology for online learning with the ability to collect and organize data and information, solve problems, and support communication exchanges between and among faculty and students (Blanchard, 2004; Syrjakow, Syrjakow, \& Szczerbicka, 2004). Thus, modeling is an appropriate tool for identifying, analyzing, and evaluating technology trends for present and future online learning. The model is presented in the form of an overview, with the objective of establishing a frame of reference for technology changes and online learning from the 1950's to 2010's. The Technology Change Model (TCM) 1950-2010 has a seven step process for advancing online learning: design for online learning; produce online linked systems; digital online network distribution; online network operation; online system expansion; online system utilization; and, improved mobile computing hardware and software. 


\section{EVOLUNTIONARY TRENDS AND MOBILE LEARNING}

The rise of mobile devices must be considered the most important shift in business. The question must be asked - why not with online education. With mobile devices now mainstream, educators need to leverage student desires to use their personal devices for school. Using mobile awareness, schools can connect with online students and create a more personal relationship. This relationship can provide the student with opportunities to download dynamic learning from digital displays. These digital displays include mobile phones, notebooks, and tablets. Indeed, there is rapid expansion of wireless synchronization between media devices with Smartphones, notebooks, and tablets which should lead to a much more enhanced digital experience.

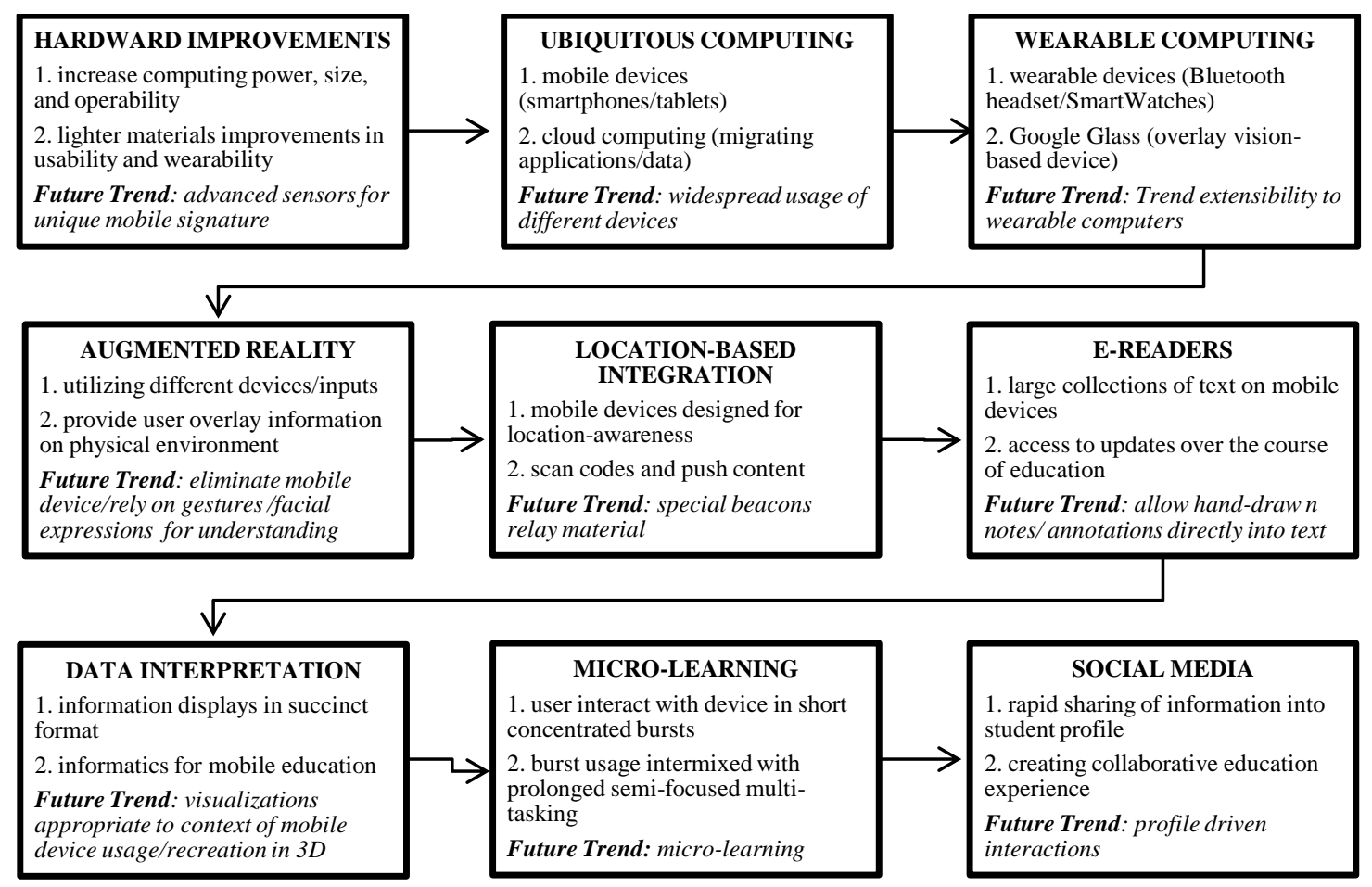

Model 2: Mobile Awareness Model for Online Learning (MAMOL)

Source: Cook \& Sonnenberg (2013)

Today, mobile phones increasingly perform a wide variety of media programming with video playback, photo displays, and media storage. Beyond the specific function of media programming, with digital display, students can filter a syllabus for class information, play an interactive business game, take a quiz, and immediately display quiz scores and overall class standing. The use of mobile devices allows for teachers and learners to interact anytime from anywhere with seamless technology and borderless networks. The task of extrapolating and predicting the future of mobile learning is a justifiably difficult task, but predicting trends can be accomplished by close analysis of the products and services used currently. One can already see that increased mobile advancements have changed the way users interact with established technologies. Researchers note that more users will interact with the Mobile Web than traditional desktop Web by 2014 (Standage, 2012). Additionally, a number of innovations and inventions have been created in recent years that have yet to enter mainstream acceptance. These technologies, combined with current mobile trends and the focused application of online and mobile learning, can paint a logical picture of things to come. The ensuing sections will detail some of these predications. Specifically, distinction will be made between evolutionary near-future developments in the next five years and transformative far-future changes from ten years and beyond. Lastly, the following developments are an extension of current trends in mobile computing with possible application to the mobile learning environment. These technologies represent immediate changes already being witnessed in the mobile environment, how they will relate to mobile learning within the next five years, and possible implications. Discussion will include, hardware, new devices, and software as well as the changes in learning and cognition as a reflection of these new technologies (see Models 2 and 3). 


\section{HARDWARE IMPROVEMENTS}

Many trends and innovations are made possible by advancements in computing power, size, and operability. These developments will continue, increasing the speed of mobile devices while reducing the burden on the system's resources. Lighter materials will pave the way towards improvements in usability and wearability. Most importantly will be the device's power consumption, as the movement towards "always on" devices necessitates a way to power devices for extended periods of time. Other hardware developments of note include advancements in contextual awareness. Mobile devices already have a limited amount of information on their environment. Physical location can be derived from GPS sensors while gestures and motions can be pulled from accelerometers. In fact, research (Kaltz, Ziegler, \& Lohmann, 2005; Lohmann, Kaltz, \& Ziegler, 2007; Prasad, Buford, \& Gurbani, 2011) showed that simply the way a mobile device is handled and calls are answered can differentiate one user from another. Students will develop a unique mobile "signature" based on these data points. This information may be used for security purposes, but perhaps also for dynamic interactions. Advanced sensors in the future may track information such as temperature, sound levels, glare, and other environmental factors. The material the student is focusing on may adjust to respond to changes in context. Audio levels may rise and screen brightness may shift to compensate accordingly. Furthermore, changes in context may signal a shift in the method of distribution for the learning material. If a user is stationary, a different set of notes and teachings may be provided than for those users on the move.

\section{UBIQUITOURS COMPUTING}

Ubiquitous computing for online learning has the advantage of computing concepts whereby computational capacity is built in to everything, where one might think of these concepts as invisible computations. The rise and evolution of mobile computing is itself an extension of a larger trend in the way humans and computers interact. The term "ubiquitous computing" has been established as an environment by which computing is inherently present in all manners of day to day life (Weiser, 1993). Mark Weiser of Xerox PARC laboratory is credited as the originator of the term with regards to the advancement of computing. Weiser viewed computing in stages, with initial stages requiring users to interact with computers directly and consciously. In a later stage, the ubiquitous stage, the technology is not a distinct entity, but rather becomes a part of everyday life. The key tenant of ubiquitous computing is that technology should not require the user's complete attention. Instead, computers must act as an extension of the user, rather than a simple terminal for interaction. Weiser foresaw a number of devices in 1988, such as wearable tab devices and handheld pads, which are now realized in today's smartphones and tablets. Ubiquity is further established through the current trend in cloud computing. By migrating applications and data to the cloud, users are no longer tied to a specific device or location. This data is now available at any time from anyplace. These changes directly translate into teaching and learning, especially in the online environment. Students no longer need to sit down at a desktop computer to engage in a classroom. Mobile devices allow them access from anyplace, while cloud-based content allows access on any device. The wireless networks of the future will need to be able to sustain such widespread usage of different devices, while at the same time educational content will need to be generated to take advantage of cloud-based access. While today's environment is a great reflection of this trend, further developments in ubiquitous computing will see microprocessors built into every device imaginable. In addition, any mobile device will be expected to have wireless connectivity in order to communicate with other devices. It's important to note that while there may be more individual devices in the future, the collective sum of their parts will be intertwined into a seamless experience. Devices will no longer represent a source of static information, but a representation of us. Mobile device users will interact directly with the environment and provide a much more dynamic experience. These trends are already taking root in some smartphone mechanisms, such as smart wallets and GPS devices.

\section{WEARABLE COMPUTING}

As ubiquitous computing becomes the driving force of mobile learning, so will the need to integrate devices seamlessly with the user. Wearable computing is an extension of this trend, developing technology that a user can wear without interfering with their day-to-day activities. Some of these devices already exist, such as Bluetooth headsets, earpieces, SmartWatches, and most recently Google Glass, an overlay vision-based wearable device. Furthermore, many wearable devices find special niche markets, such as users with disabilities, healthcare, and military personnel. Likewise, education will aim to benefit from advances in this field. 
The key features of wearable computing, as a continuation of the core principles of ubiquitous computing, are permanence, extensibility, and multi-tasking. Permanence means that these devices will no longer have the distinction between "on" or "off." These devices will always be available and operational. Extensibility refers to wearable computers as an extension of ourselves, providing insight into the local environment that may not readily available to normal human perception. Multi-tasking represents our ability to operate and interact with such devices while simultaneously performing other tasks. Wearable computing will provide tremendous value to the mobile and online learning fields. Through a student's perspective, these devices provide constant and immediate feedback throughout their day regarding classroom updates, assignments, and learning material. Furthermore, these devices can provide location-based contextual information without the need for a physical educator present. For example, students working in electronics may perform assignments on a simple breadboard or logic circuitry. A mobile device will allow the student to gain additional information, such as what each component is that they are handling, where it should be located, and any environmental hazards they might not be aware of. Furthermore, educators can receive feedback from each student as they perform these assignments in real-time.

The future of wearable computing will not stop simply at stand-alone devices. Research is underway to develop synthetic wearable "skin," a complex array of sensors and processors that can seamlessly integrate with the human body. These skins are currently simple arrays of sensory feedback that are typically integrated into larger systems. This research initially focused on mimicking human skin patterns for robotics or creating prosthetics (Someya, 2013). However, in the future, these "bioskins" will include wireless technologies and dynamic interfaces, allowing a greater degree of capability and usability. The technology could easily be integrated into any manner of functional areas, including education. Student athletes may be able to receive guidance from a coach, located miles away, simply based on the feedback of these sensors.

\section{AUGMENTED REALITY}

Augmented reality is the further realization of integration between human and machine, providing a seamless access to information without requiring a user's active input. Augmented reality is seen as the next step in ubiquitous computing, utilizing different devices and inputs to provide a user with an overlay of information about their physical environment (Cheng \& Tsai, 2013). Perhaps the most well-known example of this technology is Google Glass. A head-mounted display, Glass is a thin physical visor that resembles eyeglasses in form factor. However, instead of prescription lens, Glass contains transparent screens that show any type of digital information you can think of. Essentially, it translates the desktop interface into one that is merged with normal human perception regardless of where or what they are looking at (Google, 2013). The power of Glass comes in the augmented reality functionality, processing the immediate environment and responding with additional feedback (IEEE Spectrum, 2009). For example, with facial recognition capabilities, such an interface might be able to look up Facebook details and display them on the head-mounted display. The user then has more context and relevant information when speaking directly with the person in question. Augmented learning has incredible potential for mobile learning. In a physical classroom, students and educators alike will have immediate access to a wealth of information. As an instructor works through notes or slides, annotations may appear on a student's display to further illustrate a point in a lecture. Research has even been done on using augmented reality to allow an educator to monitor the cognition and understanding of each individual student (Zarraonandia, 2013). Using a system called the "Augmented Lecture Feedback System," an educator wears special glasses that provide an overlay for each student (Cheng \& Tsai, 2013). If a student is having trouble with a topic, they indicate so on a mobile device. This gets relayed to the educator's glasses, which display a special icon over that particular student indicating they are having trouble. In the future, this technology might be further enhanced to completely eliminate the mobile device input from students and instead rely on subtle gestures and facial expressions to indicate understanding (Lahey, Girouard, Burleson, \& Vertegaal, 2011). The future of augmented reality in mobile learning will depend heavily on how intrusive these devices are to the user. While physical glasses are fairly undemanding, future technology will be more seamlessly integrated. Research at the University of Washington has led to augmented reality lightemitting diode (LED) displays on contact lens, providing the same functionality of a glass screen overlay, but at a miniaturized factor. Further research at Ghent University has developed curved liquid-crystal display (LCD) display for contact lenses, allowing a much broader range of possibilities than a simple LED (Bernstein, 2012; Cheng \& Tsai, 2013; Fluid, 2013). 


\section{LOCATION-BASED INTEGRATION}

Mobile devices are optimally designed to take advantage of location-awareness, the ability to interact with and interpret a user's immediate surroundings. This is evident with the advent of augmented-reality technology, but there are other targeted location services available for mobile education. One example, already in use in a number of museums, is the use of contextual audio feedback. These technologies exist as simple applications, scan codes at particular exhibits, or specialized devices that push content to nearby phones. However, new developments are taking the possibilities one step further. One of the most interesting applications of "content push" systems is presented in Apple's iBeacon product (Apple Insider, 2013; Dilger, 2013). These devices are beacons that emit localized content in a physical area. Cheap in design and easily configured, the beacon will automatically push content out to any device that is listening in a particular area. Initially designed for commercial use with small businesses, these devices could be tailored for education (Apple Insider, 2013; Dilger, 2013). A student could be visiting a manufacturing plant or facility, where at particular points in the building, special beacons would relay material that would teach the students about what they were focusing on. This would facilitate a hands-on teaching experience without necessarily needing an educator present.

\section{E-READERS}

Since the mainstream introduction of eBook Readers such as the Nook and Kindle in 2007, users have become more accustomed to reading large collections of text on mobile devices. This trend will likely continue in the education realm. Many states and countries already have initiatives planned to phase out traditional textbook learning in favor of tablet-based devices. California has proposed replacing student textbooks with eBooks and South Korea has mandated that all academic institutions phase out physical textbooks in favor of tablets and ereaders by 2015 (www.siliconrepublic.com, 2013). The benefits of e-readers are clear; they save students money on purchasing books and they eliminate the need for costly updates and editions. With each eBook, a student may have access to countless updates over the course of their education. E-Readers occasionally suffer from some of the drawbacks that all mobile devices face such as glare in sunlight and battery life. Further developments will not only improve the E-Reader in terms of hardware performance, but may fundamentally alter the way students interact with textbooks. New devices, like the NoteSlate, allow students to hand-draw notes directly into text, make annotations, and physically interact with learning materials in much the same way they traditionally have done with paper-based materials (Noteslate, 2013).

\section{DATA INTERPRETATION}

The mobile environment is a heavily data-driven environment, conveying large amounts of data from various sources all onto a small handheld device. Mobile devices have a limited amount of viewable screen space to present and communicate ideas and concepts with. Therefore, it is necessary to create information displays that intelligently present vast amounts of data in a succinct format. Informatics is the academic study of information processing and a rapidly growing sub-domain in a number of areas, including health care, crisis management, military analysis, and business development (Greenes, 1990). Mobile learning will need to incorporate many concepts of informatics in the future, whether directly or indirectly. Future devices will be able to convert large amounts of course material into visualizations that are appropriate to the context of mobile device usage. For example, instead of reading static text about anatomy, medical students will be able to browse a full recreation of the human body in 3D. The underlying data will be the same, but the presentation will be much more intuitive.

\section{MICRO-LEARNING}

As mobile devices have changed the way users handle computers, they have also changed the way users interpret and process data. Mobile devices provide immediate access to the Internet and with it a vast array of knowledge. It has been well-documented that the Internet has already changed the way humans collect and retain information (Arsham, 2002). Mobile learning has further accelerated this shift in cognitive processing. It's important to understand these changes and discuss the future implications to developing online learning tailored to this mindset. One of the basic patterns of mobile device practice is the tendency towards "burst usage." This is the process by which most users interact with a device in short concentrated bursts, intermixed with prolonged semi- 
focused multi-tasking. As focused usage diminishes, the need to divide content into more manageable sections is essential. Educators in the future will have to implement a system of "micro-learning," redeveloping content into smaller bites, while still maintaining the overall cohesive focus of the course. Certain subjects will likely be better served by this approach than others. Programmers learning specific commands in a step-wise fashion may be more adept at this approach than a law student understanding an intricate, intertwined set of rules and regulations. The classroom of the future may not fully adopt this type of rapid, miniaturized learning structure, but it may implement it to a certain degree to provide introductory content at a manageable level.

\section{SOCIAL MEDIA}

No discussion of mobile devices is complete without discussing the impact social media has had with the way we communicate with each other and the world. In many ways, the rise of mobile device usage and social media are intertwined. Mobile devices provide the capabilities and context that allows the rapid sharing of information that social media relies upon. In turn, the popularity of such services helps drive the mobile device industry. In fact, many social networking services were originally intended for academic pursuits. Facebook itself was designed specifically for college students to connect with one another. Today's students typically have a number of social media outlets. In the future, we will see these disparate entities merged into a cohesive student profile. Social media will become more refined and more powerful in creating a collaborative educational experience. Combined with such technologies as augmented reality, students with mobile devices will be able to present themselves entirely differently. Imagine a scenario by which a student presents a paper at a conference. This student has a collective profile, ranging from their academic background to what skills and topics they are interested in. Audience participants with a device like Google Glass will have this information immediately displayed when looking at this speaker. This "profile" can drive every interaction that student has, whether it is someone accessing their paper on a tablet to an employer interested in a student's credentials.

\section{TRANSFORMATIVE TECHNOLOGIES}

Emerging technology trends are now building over the Web. Devices are becoming more inter-connected to create a more coherent user experience. We can expect changes in our technology, media, and telecommunications ecosystems. Ultimately, advancements in hardware will continually drive the future of mobile technology possibilities (see Model 3).

\begin{tabular}{|c|c|c|}
\hline $\begin{array}{l}\quad \text { INTEGRATED COMPUTING } \\
\text { 1. direct fusion between technology } \\
\text { and human users } \\
\text { 2. interactions between digitial } \\
\text { components and biological or } \\
\text { physiological processes } \\
\text { Future Trend: embedded information } \\
\text { systems }\end{array}$ & $\begin{array}{l}\text { IMMERSIVE TECHNOLOGIES } \\
\text { 1. simulate and extend physical } \\
\text { classroom presence into user location } \\
\text { 2. replace user physical surrounding } \\
\text { with computer-simulated alternative } \\
\text { Future Trend: full virtual reality }\end{array}$ & $\begin{array}{l}\quad \text { ADAPTIVE COURSES } \\
\text { 1. artificial intelligence for adjusted } \\
\text { teaching methods } \\
\text { 2. customized knowledge framework } \\
\text { for student categories } \\
\text { Future Trend: derive appropriate } \\
\text { student learning module from core } \\
\text { content }\end{array}$ \\
\hline$\downarrow$ & & \\
\hline $\begin{array}{l}\quad \text { LANGUAGE PROCESSING } \\
\text { 1. voice control learning mechanism } \\
\text { 2. speed/effectiveness translation } \\
\text { speech to text and vice versa } \\
\text { Future Trend: immediately translate } \\
\text { any language with Natural Language } \\
\text { Processing }(N L P)\end{array}$ & $\begin{array}{l}\text { 1. devices with wearable visors, } \\
\text { watches, biological sensors, and } \\
\text { holographic projectors } \\
\text { 2. circuitry in flexible material } \\
\text { Future Trend: sensors with malleable } \\
\text { substance to alter shape of digital } \\
\text { objects }\end{array}$ & $\begin{array}{c}\text { BEYOND ? } \\
\text { holodeck space } \\
\text { core processing technology } \\
\text { seamless sheet overlays } \\
\text { matter conversion }\end{array}$ \\
\hline
\end{tabular}

Model 3: Transformative Technologies for Online Learning (TTOL)

Source: Cook \& Sonnenberg (2013)

As miniaturization and nanotechnology improves, so will the capabilities and possibilities of mobile devices as they relate to mobile learning. Miniaturization can be explained as a trend to manufacture smaller 
mechanical, optical, and electronic products and devices (Hu, Shang, Xu, Lin, Snyder, \& Wang, 2011). According to Hu et al. (2011), nanotechnology was the construction and use of functional structures designed from atomic or molecular scale with at least one characteristic dimension measured in nanometers. Nanotechnology was important because it provided understanding about materials and devices that were likely to impact many fields - such as new generations of biological sensors and mechanical properties (Hu et al., 2011). The subsequent section details advancements that could arise in ten years and beyond, as cost barriers and device limitations give way to new and remarkable.

\section{INTEGRATED COMPUTING}

The next step from wearable computing is the direct fusion between technology and human users. This would involve direct interactions between digital components and biological or physiological processes. Advancements such as bioskins and micro-sensors can provide information on a user's physical self, but future technology will go far beyond simple sensors. Of particular interest in the field of education are the reactions and signals of brain wave patterns. We may soon be able to monitor these patterns with mobile devices to better understand cognitive development directly in a classroom setting. The process of electroencephalography (EEG) measures the electric activity present in the human scalp and maps it to develop patterns and ascertain the response to certain stimuli (Niedermeyer, 2005). EEG measures changes in voltage that result from shifts in current within the neurons of the brain. While these technologies are fairly limited today, future research will take this far and beyond what we can imagine. As our understanding of the human mind develops, so too will the devices that interact with the brain. A more detailed understanding of neuroscience may lead to devices that can assist with students that suffer from a wide range of learning disabilities. If a device measures favorably with a certain teaching approach, further efforts could be made to pursue a particular course of action more readily than waiting a prolonged period of time to determine its effectiveness. Integrated technologies might even be utilized to combat issues such as plagiarism and academic conduct. Students prone to cheating on an exam may be highlighted by subsystems that monitor human behavior in a classroom setting. Increased heartbeat and rapid eye movement might be monitored by onboard devices, which in turn signal educators of potential academic dishonesty. In such a manner, a single educator could have much more control over a classroom setting. Integrated technologies need not only focus on monitoring the user; they may also act as extensions to interact with the environment. Finger sensors in development at MIT are a good example of such an approach. These devices focus on what objects the finger points at and then converts any relevant data into something meaningful for the user (Nanayakkara, 2013). In the future, such devices would be embedded systems providing information to the student and feedback to the instructor. For example, finger sensors might create a map of where a student plays keys on a piano. The instructor in turn can read this map and get an idea of what trouble the student is running into, all without ever seeing or hearing the student play a single note.

\section{IMMERSIVE TECHNOLOGIES}

Immersive technology aims to simulate or extend a physical classroom presence into a single user's location. The key concept here is simulation, creating a digitized representation of what the student would normally experience in a typically academic facility. While integrated technologies aim to extend a user into their physical surroundings, immersive technologies aim to replace a user's physical surroundings with a computer-simulated alternative. Many of the far-off futuristic technologies are represented in this realm, concepts like virtual reality, holograms, telepresence, and haptic feedback. Some of these technologies are closer than one might imagine. Virtual reality and simulation tools have been in use for years, especially in the military domain (Bailenson, 2013). As the technology becomes cheaper and more accessible, education and mobile devices will begin to integrate them into their core functionality. Head-mounted displays already exist in a number of forms and fashion. In the future, we may have the option to swap between augmented-reality vision and virtual-reality seamlessly. The trick will be in how we translate physical movements into this digital realm. One device, the Virtuix Omni, already achieves limited translation of physical movement into movement in a simulated environment (Virtuix, 2013). As the form factor requirements become more usable, the major hurdles that full virtual reality face will be overcome. 


\section{ADAPTIVE COURSES}

The future of online education will incorporate advances in artificial intelligence to the point that a course will be able to dynamically adjust teaching methods to best suit each individual student. Courses will develop a learning model based off various interactions with student types, and then create a customized knowledge framework for student categories. For example, a basic knowledge framework might incorporate levels of interaction with the educator as well as levels of interaction with the classroom participants. This could then be subdivided to create four distinct subgroups such as the "Agent," "Nomad," "Keeper," and "Analyst" (Razek, 2013). The Agent prefers heavy interaction with the facilitator and low interaction with peers. The Analyst is the opposite, preferring communication at the peer level over those with educators. The adaptive course of the future will factor in a student's past academic history to derive an appropriate learning module out of the core content provided by the course developers. In this manner, certain assignments may be designated to the student types most adept at pursuing and engaging them. For example, students with an inclination towards self-analysis and critical thinking may be automatically assigned to writing research papers while students that benefit from group interactions may be assigned collaborative projects instead.

\section{LANGUAGE PROCESSING}

A tremendous amount of content viewed on mobile devices is typically text based, especially in online classrooms. In addition, most users interact with their online classrooms in a traditional textual input mechanic, such as forum posts or emails. The use of voice as a control and learning mechanism can greatly increase the speed and effectiveness of online learning. Tools like Apple's Siri and Google Voice rely on a mechanism called Natural Language Processing (NLP) to translate speech to text and vice versa. It can help to make online learning smarter, by analyzing the meaning of content and taking suitable actions for users (Sateli, Cook, \& Witte, 2013). However, NLP is still in its infancy. Due to its complexity, NLP has not found widespread adoption in today's devices. Future research in NLP will open up the possibilities of this technology; enabling devices to not only interact in their own language, but any other language possible. Language and dialect barriers will recede as users are able to immediately translate their inputs and outputs from one language to another. This will greatly increase the ability for distance learning on mobile devices.

\section{MALLEABLE COMPUTING}

As form factor technology advances, the capabilities of integrating processors and circuitry into any number of objects increases. Soon, mobile devices will represent a myriad of wide-ranging applications, from wearable visors and watches to biological sensors and holographic projectors. Traditionally, mobile devices have been rigid in form factor, but this will change as nanotechnology creates new methods of creating circuitry in flexible material. The bioskin sensors are a good example, but this technology can go much further. Imagine the possibility of individual sensors and circuitry embedded in a malleable substance, one that can be molded into various shapes and sizes. The ability to physically alter the shape of a digital object will allow a wide range of educational opportunities. Students in manufacturing and design can create rapid prototypes out of "digital clay" in the real physical world. These devices will have the added effect of providing haptic feedback to the user to better understand the physical dynamics of their product.

\section{CHALLENGES}

Mobile technology faces critical issues in the near future, ones that will need to be addressed if mobile devices are to adequately handle increased usage. One of the most important issues facing mobile networks is the limitations of the wireless networks. Cellular networks, which handle the majority of mobile bandwidth, are structured differently than traditional desktop-based networking. The infrastructure of wired networks is much more robust and intended for heavy data loads. Users have come to expect a certain amount of response time in browsing on desktops and have carried those expectations to the mobile environment. The problem is that mobile web usage is expanding at a much more rapid rate than the infrastructure. Short term solutions to this dilemma include the distribution of more cell towers, offloading data onto wired networks via Wi-Fi, or licensing more parts of the frequency spectrum to accommodate more channels of data (Mace, 2011). However, these solutions may be too cost-prohibitive for companies to implement at a large scale. 
Other challenges present in the mobile market include usability and privacy concerns. Usability refers to the intuitiveness and operability of mobile devices, specifically how easy they are for users to learn and interact with. Privacy refers to the confidentiality and security of student information and data. The rate of device development has traditionally outpaced the research in Human-Computer Interaction (HCI) and security usage factors. As mobile learning incorporates a wider range of devices, usability and proper data handling will play a major part in determining the adoption rate and success of newer technologies such as augmented reality and wearable computing.

\section{CONCLUSIONS AND RECOMMENDATIONS}

This paper contended that technology changes advanced online education. A review of the literature examined technology vicissitudes, online education systems, along with mobile device literature from 1950 to our present time in order to build a picture of past, current, and future trends for online learning and technology changes. The object of this descriptive study was to create several models (TCM, MAMOL, TTOL) to understand technology changes for mobile devices and how this understanding can be used for online learning. The application of this approach led to a better definition of mobile awareness and greater online visibility relative to the selection of the appropriate model criteria and requirements. Several models were created to show hardware and software advancements to design mobile awareness which highlighted borderless networks to benefit online teaching and learning groups.

Technology is rapidly transforming the way education is delivered through online and mobile systems. The online learning experience today is a fundamentally different environment than the traditional classroom. Online education takes advantage of innovative collaborate tools and their applications to create models of borderless online networks. With borderless online networks from innovative devices, hardware, and software, we can create dynamic online learning opportunities. Complex technologies allow more people to gain access to broader areas of information. Internet communication has drastically increased the abilities of educators to reach a global scale. The rise of mobile devices has also given online educators leverage to engage students on a personal level while allowing students the ability to interact with their classroom in any location. These advantages provide the student with fully dynamic learning through any digital outlet.

While current technologies are indeed innovative, future developments will take the online learning experience into new and uncharted territory. Predicting trends may be difficult, but it can be accomplished by examining the devices and technologies used today and extrapolating forward. These technologies, combined with current trends, have been analyzed in this paper and compiled into a workable technology model. The application of the models outlined in this study will allow educators and academic institutions to position themselves at the forefront of online learning for years to come.

Perhaps the most important factor of innovation is the forward march of hardware advancements. As miniaturization, resource management, and power consumption technologies improve, this factor will influence the success of adoption in almost every other area in mobile technology. All of the highlighted factors are outlined in detail within the attached models and come with examples of devices and systems that may play an important role in online learning. The implementation of these models will provide educators with much greater insight into the future and may even allow them to influence or build on them to greater heights.

Mobile technology will play a key factor in the future growth of online learning, and with it comes several recommendations. The trend towards ubiquitous and wearable computing will necessitate more integrated devices, allowing a much greater range of feedback both for the student and the educator. Specific features of these devices, such as location-integration and data interpretation, will provide much more dynamic means of interacting with complex information that was previously impracticable in an online environment. Platforms and technologies, such as social networks and NLP, will allow students to communicate and learn across cultural, political, and language barriers. Adaptive course mechanisms will also allow greater freedom in online learning content delivery while content itself will need to be generated specifically designed to take advantage of the micro-learning method prevalent in the mobile space. 
What can we imagine for online learning and beyond, moving virtual reality towards online learning? Is it so farfetched to think of a holodeck and immersive media in the online classroom? Imagine integrated devices providing simulated environments with seamless overlays; with only the touch of a floating screen we could interact with the next generation of online learning. Malleable devices and 3D printers could provide an untold level of interaction and dynamic matter creation and conversion. This vision is not so far beyond our grasp. Our recommendation is further study into these models for the online classroom of the future.

\section{AUTHOR INFORMATION}

Dr. Catherine W. Cook was born in Paris, France, and later graduated from high school and colleges in the states of Florida and Ohio. Dr. Cook worked with Pan American Airways and the Boeing Company in customer service. After leaving the airline industry, she completed her MBA and doctoral studies and began her academic career. During this career, she has served as Dean of Education, Associate Dean of Academics, and Department Chair for Accounting, Business Administration, and Graduate Studies. She received the top teaching award while serving as a faculty member. Dr. Cook was awarded a Workforce Challenge Grant and was a Co-curriculum Framework Writer with Indian River Community College for the Hospitality and Tourism Program. She has been certified by the Institute for American Hotel and Motel Association as well as the Institute for Travel Career Development in Tourism. Her research areas are in changing socio-political foundations of business enterprise in America, educational growth patterns, online education, tourism, women's leadership, and curriculum development and

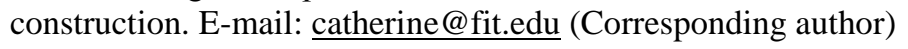

Christian Sonnenberg, Ph.D., joined the College of Business at Florida Institute of Technology in 2013 as an assistant professor in Information Systems and Academic Chair for the Online Master of Science in Information Technology (MSIT) and MBA in Information Technology Management. He earned his doctorate in 2013 in Computer Science from Florida Tech with a research focus in handheld and mobile usability. He also earned his bachelor's and master's degrees in Computer Science and Software Engineering respectively from Florida Tech. Previously, Dr. Sonnenberg has worked as a software engineer for Harris Corporation Government Communications Systems Division (GCSD) in Melbourne, FL since 2003. While there, he worked in a number of areas including directional wireless networks, cellular interrogation systems, and satellite image processing applications. E-mail: csonnenb@fit.edu

\section{REFERENCES}

1. Abbate, J. (1999). Inventing the internet. Cambridge, MA: MIT Press.

2. Al-Fedaghi, S. (2009). Interpretation of Information Processing Regulations. Journal of Softwater Engineering Applications, 2, 67-76.

3. Alison D. (2010). Executives Demand Communications Arsenal. InformationWeek. September 30, 2010. Retrieved October 5, 2010.

4. Apple Insider (2013). Retrieved 9/23/2013 from http://appleinsider.com/articles/13/06/19/inside-ios-7ibeacons-enhance-apps-location-awareness-via-bluetooth-le

5. Aranda. N. (2006). A brief history of online education. Retrieved 6/24/2013 from http://ezinearticles.com/?A-Brief-History-of-Online-Education\&id=248882

6. Arsham, H. (2002). Impact of the internet on learning and teaching. USDLA Journal, 16(3), 43-52.

7. Balakrishnan, V., \& Lay, G. (2013). Mobile wireless technology and its use in lecture room environment: An observation in Malaysian institutes of higher learning. International Journal of Information and Education Technology, 3(6), 634-637. doi: 10.7763/IJIET.2013.V3.351

8. Bailenson, J. (2013, March). Keynote speaker: Infinite reality: Avatars, Eternal life, new worlds, and the dawn of the virtual revolution. In Virtual Reality (VR), 2013 IEEE.

9. Barras, C. (2007). Illuminating the net's dark ages. Retrieved 6/26/2013 from http://news.bbc.co.uk/ 2/hi/technology/6959034.stm

10. Baset, S., \& Schulzrinne, H. (2004). An analysis of the Skype peer-to-peer internet telephony protocol. New York, NY: Department of Computer Science, Columbia University.

11. Bates, T. (2012). A timeline of early online education pioneers. Retrieved 6/24/2013 from Physics.illinois.edu; ourroots.ca; web.njit.edu; eric.ed.gov; coastline.edu 
12. Berners-Lee, T. J. (1992). World-Wide Web: Information universe. Electronic Publishing: Research, Applications and Policy.

13. Berners-Lee, T., \& Fischetti, M. (1999). Weaving the web: The Original design and ultimate destiny of the World Wide Web by its inventor. San Francisco, CA: HarperSanFrancisco.

14. Bernstein, J. (2012). Invention awards: Augmented-reality contact lenses. Popular Science, 5 June 2012.

15. Biondi, P., \& Desclaux, F. (2006). Silver needle in the Skype. EADS Corporte Research Center DCR/STI/C: Suresnes, France.

16. Blanchard, B. (2004). Logistics engineering and management (6 $6^{\text {th }}$ Ed.) Upper Saddle River, NJ: Pearson/Prentice Hall.

17. Boettcher, J., \& Conrad, R. (2004). Moving teaching and learning to the web. Phoenix, AZ: League for Innovation in the Community College.

18. Borenstein, N. (1993). A user agent configuration mechanism for multimedia mail format information. Retrieved 9/19/2013 from http://tools.ietf.org/html/rfc1524

19. Bower, J., \& Christensen, C. (1995). Disruptive technologies: Catching the wave. Harvard Business Review, January-February 1995.

20. Cheng, K., \& Tsai, C. (2013). Affordances of augmented reality in science learning: Suggestions for future research. Journal of Science Education and Technology, 22(4), 449-462.

21. Chess, D. (1998). Security issues in mobile code systems. Lecture Notes in Computer Science, 1419, 1-14.

22. Choudhry, R. (2013). Videoconferencing, communicating with the world and beyond. UCL Information Service Division. Retrieved 6/26/2013 from http://www.ucl.ac.uk/isd/staff/research_services/governance/ riisg/RIISG__Draft_Minutes____4_6_2013_RC.final.pdf

23. Cook, C., \& Sonnenberg, C. (2013). Technology and online education: Models for change. Melbourne, FL: Nathan M. Bisk College of Business.

24. Daft, R., \& Lengel, R. (1986). Organizational information requirements, media richness and structural design. Management Science, 32(5), 554-571.

25. Davis, C. (1980). Fundamentals of PLATO programming. Computer-based Education Research Laboratory, University of Illinois, Urbana, Illinois.

26. Dilger, D. (2013). Inside iOS 7: iBeacons enhance apps' location awareness via bluetooth LE.

27. Fenell, Z. (2013). What Are the tools for internet communication? Retrieved 9/18/2013 from http://www.ehow.com/facts_5720183_tools-internet-communication.html

28. Fluid, MIT Media Lab. Retrieved 9/23/2013 from http://fluid.media.mit.edu/

29. Google Glass (2013). Retrieved 9/22/2013 from http://www.google.com/glass/start/

30. Greenes, R., \& Shortliffe, E. (1990). Medical informatics: An emerging discipline with academic and institutional perspectives. Journal of the American Medical Association, 263(8), 1114-20.

31. Gruzd, A., \& Staves, K. (2011). Trends in scholarly use of online social media. Position paper presented at the Workshop on Changing Dynamics of Scientific Collaboration, the 44th Annual Hawaii International Conference on System Sciences (HICSS). Available at http://dalspace.library.dal.ca/handle/10222/14427

32. Hilbert, M., \& Lopez, P. (2011). The world's technological capacity to store, communicate, and compute information. Science 1, 332(6025), 60-65.

33. Hiltz, S., \& Turoff, M. (1993). Network nation. Massachusetts Institute of Technology.

34. Hobbes, R. (2011). Hobbes' internet timeline 10.2. Retrieved 6/26/2013 from http://www.zakon.org/robert/internet/timeline/

35. Hsu, H., Lin, F., Sun, Y., \& Chen, M. (2012). A novel protocol design and collaborative forensics mechanism for VoIP services. Journal of Communications, 7(2), 132-142.

36. Hu, Y., Zhang, Y., Xu, C., Lin, L., Snyder, R., \& Wang, S. (2011). Self-powered system with wireless data transmission. DARP and the U. S. Department of Energy, Basic Energy Sciences.

37. IEEE Spectrum (2009). Augmented Reality in a contact lens - IEEE Spectrum. Retrieved 9/23/2013 from http://spectrum.ieee.org/biomedical/bionics/augmented-reality-in-a-contact-lens

38. Kaltz, J., Ziegler, J., \& Lohmann, S. (2005). Context-aware web engineering: Modeling and applications. (PDF). Revue d'Intelligence Artificielle, 19(3), 439-458. doi:10.3166/ria.19.439-458

39. Kanellos, M. (2003). Moore's law to roll on for another decade. Retrieved 6/25/2013 from http://news.cnet.com/2100-1001-984051.html

40. Koscielniak, B. (2003). Johann Gutenberg and the amazing printing press. Boston, MA: HoughtonMifflin. 
41. $\quad$ Kurzweil, R. (1999). The age of spiritual machines. Viking, pp. 30-32.

42. Kurzweil, R. (2001). The law of accelerating returns. Retrieved 6/26/2013 from http://www.kurzweilai.net/ the-law-of-accelerating-returns

43. Lahey, B., Girouard, A., Burleson, W., \& R. Vertegaal. (2011). PaperPhone: Understanding the use of bend gestures in mobile devices with flexible electronic paper displays. In Proceedings of $A C M C H I$ '11 Conference on Human Factors in Computing Systems, ACM Press, pp. 1303-1312.

44. Lohmann, S., Kaltz, J., \& Ziegler, J. (2007). Model-driven dynamic generation of context-adaptive web user interfaces. Lectures Notes in Computer Science, 4364, 116-125.

45. Mace, M. (2011). Mobile opportunity: The truth about the wireless bandwidth crisis. Retrieved 9/27/2013 from http://mobileopportunity.blogspot.com/2011/06/who-will-pay-for-mobile-data.html

46. Maratos, D. (2012). A brief history of online e-learning software. Retrieved 6/24/2013 from http://ezinearticles.com/?A-Brief-History-of-Online-E-Learning-Software\&id=7343970

47. Martell, J. (2013). How to choose your web conferencing software - Set your business up for success. Retrieved 9/23/2013 from http://www.webconferenceclassroom.com/how-to-guides/how-to-choose-yourweb-conferencing-software/

48. Mikael, A. The history of computer networking X. Retrieved 6/26/2013 from http://www.ehow.com/ about_6581480_history-computer-networking.html

49. Moore, G. (1965). Cramming more components onto integrated circuits (PDF). Electronics Magazine, $38(8), 4$.

50. Nanayakkara, S. (2013). EyeRing: A compact, intelligent vision system on a ring. MIT Media Lab.

51. Niedermeyer, E., \& da Silva, F. (Eds.). (2005). Electroencephalography: Basic principles, clinical applications, and related fields. Wolters Kluwer Health.

52. NoteSlate. (2013). Retrieved 9/24/2013 from http://uncrate.com/stuff/noteslate/

53. Prasad, A., Buford, J., \& Gurbani, V. (2011). Advances in next generation services and service architectures. Aalborg, Denmark: River Publisher's Series in Communications.

54. Razek, M., \& Bardesi, H. (2013). Adaptive course for mobile learning. published in Computational Intelligence, Communication Systems and Networks (CICSyN) on Computational Intelligence,

Communication Systems and Networks (CICSyN), pp. 328 - 333, 5-7 June 2013.

55. Roberts, L. (1967). Multiple computer networks and intercomputer communication. Retrieved 7/17/2013 from http://www.packet.cc/files/multi-net-inter-comm.html

56. Rosenbloom, R., \& Spencer, W. (Ed.). (1996). Engines of innovation. Boston, MA: Harvard Business School Press.

57. Ruland, N. (2013). List of communication tools. Retrieved 6/26/2013 from http://www.ehow.com/ info_8075542_list-communication-tools.html

58. Sateli, B., Cook, G., \& Witte, R. (2013). Smarter Mobile apps through integrated natural language processing services. In Mobile web and information systems (pp. 187-202). Springer Berlin Heidelberg.

59. Schatzberg, E. (2006). Technik Comes to America: Changing meanings of technology before 1930. Technology and Culture, 47, 486-512.

60. Shane, S. (2009). Technology strategy for managers and entrepreneurs. Upper Saddle River, NJ: Pearson/Prentice Hall.

61. Singer, C., Holmyard, E., Hall, A., \& Williams, T. (1958). A history of technology (Volume 3). Oxford University Press.

62. Someya, T. (2013). Bionic skin for a cyborg you. IEEE Spectrum.

63. South Korea to move all students to tablets and e-books. Retrieved 9/22/2013 from http://www.siliconrepublic.com/innovation/item/22483-digsch2010/

64. Standage, T. (2012). Live and unplugged. The Economist, 12 November 2012.

65. Syrjakow, M., Syrjakow, E., \& Szczerbicka, H. (2004). Tool support for performance modeling and optimization. Proceedings of the Fifth Asia Pacific Industrial Engineering and Management Systems Conference, 2004.

66. Tennenhouse, D., Garland, S., Kaashoek, S., \& Kaashoek, M. (1996). From internet to activenet, Laboratory for Computer Science, MIT Press.

67. The Conversation. World Wide Web creator sees open access future for academic publishing. Retrieved 9/24/2013 from http://theconversation.com/world-wide-web-creator-sees-open-access-future-for-academicpublishing-11837 
68. Virtuix Omni (2013). Retrieved 9/23/2013 from http://www.virtuix.com/

69. Weiser, M. (1993). Some computer science issues in ubiquitous computing. Communications of the ACM, 36(7), 75-84.

70. Yates, R. (2013). Educational technologies to support new directions in teaching practice. International Journal of Information and Education Technology, 3(6), 602-606. doi: 10.7763/IJIET.2013.V3.344

71. Zarraonandia, T., Aedo, I., Díaz, P., \& Montero, A. (2013). An augmented lecture feedback system to support learner and teacher communication. British Journal of Educational Technology, 44, 616-628. 